\title{
Perforation thresholds and safety factors in in vivo coronary laser angioplasty
}

\author{
TIMOTHY J BOWKER, * KIM M FOX, * FRANK $W$ CROSS, $\dagger$ \\ PHILIP A POOLE-WILSON, * STEPHEN G BOWN, $†$ ANTHONY F RICKARDS *
}

From ${ }^{\star}$ the National Heart Hospital, and + University College Hospital, London

SUMMARY Laser angioplasty can cause early (acute perforation) or late (stenosis or aneurysm) complications. To find how much intravascular laser energy can be delivered via a $100 \mu \mathrm{m}$ core optical fibre passed down a balloon angioplasty catheter without causing angiographic abnormalities up to 10 days later, argon laser energy was delivered percutaneously under radiographic screening to the coronary circulation of 12 normal closed chest dogs. With the balloon inflated, sequential laser pulses were delivered to the same site. Angiograms were recorded before, immediately, and again at one week, after laser delivery. There were two laser-induced perforations (both fatal). Mechanical perforation with the $100 \mu \mathrm{m}$ fibre occurred four times, but there were no haemodynamic sequelae. To find the acute perforation threshold of similar sized arteries to energy delivered via the bare $100 \mu \mathrm{m}$ core fibre, the tip of which was held in contact with the luminal surface, 32 argon laser pulses were delivered transluminally in vivo to separate sites in normal rabbit iliac and canine coronary arteries. The acute perforation threshold with energy delivered via the angioplasty catheter lay between 6 and $10 \mathrm{~J}$ and that without the balloon angioplasty catheter lay between 3 and $4 \mathrm{~J}$. After delivery of up to $6 \mathrm{~J}$ via a balloon angioplasty catheter, there were no angiographic abnormalities at one week. Fibre optic transluminal delivery of laser energy may improve the primary success rate of, and perhaps widen the indications for, coronary angioplasty.

Since 1977 it has been possible to revascularise human myocardium percutaneously by balloon angioplasty. ${ }^{1}$ Originally application of this technique was thought to be limited, but the indications for percutaneous transluminal coronary balloon angioplasty have widened. There are now only two main limitations to the technique. These are the ability of the operator to cross the anteromatous lesion with the guide wire and balloon, and restenosis, which occurs in about $30 \%$ of patients, usually within 3-6 months of the procedure. ${ }^{23}$

Laser energy can be delivered transluminally via an optical fibre introduced percutaneously to vaporise intraluminally some of the occluding atheroma. This should enhance the operator's ability to cross the lesion. Use of a laser in conjunction with balloon angioplasty ("laser-assisted balloon angioplasty") may extend the technique to those lesions which are

Requests for reprints to Dr Timothy J Bowker, The National Heart Hospital, Westmoreland Street, London W1M 8BA.

Accepted for publication 8 October 1987 not attempted because current angiographic preselection indicates that they are "uncrossable". Whether laser energy could reduce the limitation of restenosis is uncertain, but this possibility can be evaluated only if the laser technique becomes clinically applicable.

The safety of the technique depends on the ability to vaporise luminal atheroma without causing undue damage to the subjacent normal arterial wall. This requires a reliable intracoronary delivery system and the definition of the characteristics that will not cause either immediate vessel perforation or longer term thermal damage. There are reports of relatively high in vitro ${ }^{4}$ and in vivo ${ }^{5}$ vessel perforation rates in various normal and atheromatous models and the late appearance of aneurysms in arteries treated by laser. ${ }^{6}$

The present study had three aims. The first was to test in vivo a prototype system for the percutaneous transluminal delivery of laser energy to the coronary circulation. The second was to find the acute in vivo perforation threshold of arteries that were the same size as those of the human epicardial coronary circulation. Intravascular argon laser energy was 
delivered with the tip of a bare laser fibre deliberately positioned tangentially in contact with the luminal surface of the artery and then with the laser fibre tip protruding from within an inflated balloon angioplasty catheter, so as to minimise direct contact between the fibre tip and arterial wall. The third aim was to study the immediate and longer term radiographic effects of different argon laser pulses (identified in a previous in vitro study ${ }^{7}$ as being appropriate for vaporisation of atheroma) delivered via the angioplasty catheter to the normal canine coronary circulation that might have a bearing on the late appearance of perforations, stenoses, or aneurysms. Thus we hoped to find conditions for the safe delivery of laser energy to the normal coronary circulation.

\section{Methods}

A Cooper Medical Aurora laser, capable of delivering up to $7 \mathrm{~W}$ of argon laser power, was coupled to a 100 $\mu \mathrm{m}$ core diameter optical fibre via an electronic shutter. The power output from the distal end of the fibre $(1.0-3.0 \mathrm{~W})$ was measured with a calorimeter and power meter, before and after each series of energy deliveries to each animal.

\section{ENERGY DELIVERY BY BARE FIBRE}

A left lateral thoracotomy was performed under general anaesthesia on two normal greyhounds. The left coronary artery was cannulated directly with the bare optical fibre and the tip was passed distally to different sites within its branches. The position of the fibre tip was checked by direct inspection of the laser's aiming beam (low power $<1 \mathrm{~mW}$ ) at the site at which it was transilluminating the arterial wall (fig 1). At each arterial site, the fibre tip was deliberately

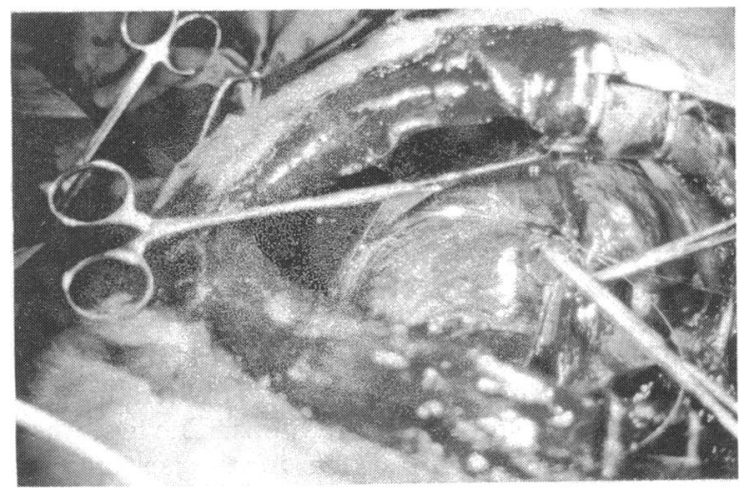

Fig 1 Dog 1 at thoracotomy, with heart brought up on pericardial cradle. An optical fibre was inserted via an arteriotomy into left anterior descending coronary artery. There is laser transillumination from the fibre tip seen just below the tip of the central pair of forceps. positioned up against the luminal surface of the vessel, and a single laser pulse (the energy of which $c$. was varied from site to site) was delivered. The $\vec{\Rightarrow}$ presence or absence of acute vessel perforation was then immediately assessed, by the presence or absence of blood leaking from the vessel. The animals were then killed and their hearts excised.

The abdominal aorta and iliofemoral arteries were exposed by laparotomy in five anaesthetised rabbits. A carotid cut down was performed and the artery was cannulated with the bare optical fibre, which was passed via the descending aorta to the abdominal aorta, the wall of which could be transilluminated with the laser's aiming beam. The fibre tip was advanced to various different sites in both iliofemoral arteries (its exact position being ascertained from the aiming beam). At each arterial site the fibre tip was positioned in direct contact with the luminal surface of the vessel, and a single laser pulse (the energy of which was varied from site to site) was delivered. The presence or absence of acute vessel perforation was then assessed. The animals were then killed and the lasered vessels were excised.

Overall in both the rabbit and dog experiments, 32 separate laser pulses were delivered to 32 separate arterial sites. The range of pulse energies delivered was $0 \cdot 2-7 \cdot 0 \mathrm{~J}$.

\section{BALLOON ANGIOPLASTY CATHETER ENERGY DELIVERY}

For the experiments with balloon angioplasty catheter energy delivery, twelve greyhounds were used. Each dog was anaesthetised and a cut down was performed to the left carotid artery, through which a $8.3 \mathrm{~F}$ guide catheter was introduced under radiographic screening and advanced to whichever coronary ostium was most easily cannulated (the left in all but one). A pre-laser coronary angiogram was recorded.

The optical fibre was preloaded down the "through" lumen of a standard 4.3F $3.0 \mathrm{~mm}$ balloon angioplasty catheter and adjusted so that the fibre tip protruded from the catheter tip by $2-3 \mathrm{~mm}$, and the $\sigma 0$ device was inserted into the guide catheter. The $N$ sidearm of a Y connector previously attached to the N proximal end of the balloon catheter was used for the infusion of Hartmann's solution down the "through" lumen alongside the optical fibre, at a pressure of 300 $\mathrm{mm} \mathrm{Hg}$ and at a rate of $1.5 \mathrm{ml} / \mathrm{min}$.

For the first three dogs we used balloon angioplasty catheters in which the "through" and balloon inflation lumen lay side by side. Thereafter, we used $\stackrel{\odot}{\circ}$ balloon angioplasty catheters with a "through" lumen that was central to and coaxial with the balloon inflation lumen. 


\section{Initial laser delivery and angiography}

The fibre/catheter device was passed via the guide catheter under radiographic screening several centimetres into a major branch of a coronary artery. Energy was delivered according to the following protocol. A sequence of three separate laser pulses was delivered to the same site within the cannulated artery, in the following order: a $1 \mathrm{~J}$ pulse, a $2 \mathrm{~J}$ pulse, and then a $3 \mathrm{~J}$ pulse. For delivery of each individual laser pulse we used a set protocol.

(a) Radiographic contrast medium was injected to check vessel patency and integrity.

(b) The angioplasty balloon was inflated to occlude downstream blood flow.

(c) The Hartmann's perfusion was then turned on.

(d) The measured amount of laser energy was then delivered via the optical fibre during perfusion with Hartmann's solution.

(e) The angioplasty balloon was then deflated.

(f) The Hartmann's perfusion was then turned off.

(g) Radiographic contrast medium was injected to check vessel patency and integrity.

In this way, the laser energy was delivered under standardised conditions- the optical fibre being perfused locally with Hartmann's solution, and being held as centrally as possible within the vessel lumen so that contact time during the cardiac cycle between fibre tip and arterial wall would be minimised. The fibre/catheter device was then removed from the guide catheter, inspected for damage, and a postlaser coronary angiogram was recorded. The guide catheter was removed, the carotid artery was repaired, and the skin was sutured. The dogs.were then allowed to recover from the anaesthetic.

\section{Repeat angiography at 7-10 days}

The dogs were re-anaesthetised 7-10 days later. After a repeat carotid cut down a 8.3F guide catheter was introduced under radiographic screening to the ostium of the coronary artery to which laser energy had previously been delivered, and a 7-10 day postlaser coronary angiogram was recorded. Whenever it was possible either the contralateral or the other major branch of the left coronary artery was then cannulated and a pre-laser angiogram was recorded. The fibre/catheter device was then passed into the newly cannulated (and previously "un-lasered") coronary artery branch. A single $5 \mathrm{~J}$ laser pulse was delivered to this arterial branch, by the same delivery sequence as described above. On one occasion two sequential $5 \mathrm{~J}$ laser pulses were delivered to the same site.

The fibre/catheter device was then withdrawn from the guide catheter and a post-laser coronary arteriogram was recorded. If the dog survived, ventricular fibrillation was induced with intracoron- ary potassium chloride. The animal's chest was then opened and the pericardium was incised. A careful inspection was made for any free blood, fluid, thrombus, or any epicardial or pericardial damage or adhesions, particularly in the region of the vessels treated by laser. The animals' hearts were then excised.

In all the canine experiments, both initially and at repeat angiography, the dogs' electrocardiograms were continually monitored, and recordings were taken before and after laser treatment.

\section{Results}

DELIVERY OF ENERGY BY BARE FIBRE

Table 1 shows the results of the rabbit and open chest dog experiments in which the bare optical fibre was used. Vessel wall perforation never occurred with the 22 laser pulses whose energies were $3 \mathrm{~J}$ or less. Three out of five $4 \mathrm{~J}$ laser pulses caused acute vessel wall perforation, and all five of the laser pulses of $5 \mathrm{~J}$ or more caused acute vessel wall perforation.

\section{DELIVERY OF ENERGY BY BALLOON}

ANGIOPLASTY CATHETER

Table 2 shows the overall results of the closed chest dog experiments in which the optical fibre was passed within the inflated balloon angioplasty catheter.

Short term and long term effects of cumulative 1,2, and $3 J$ pulses

Of the ten dogs that received sequential delivery of three laser pulses $(1 \mathrm{~J}, 2 \mathrm{~J}$, then $3 \mathrm{~J}$ ) to the same site in their coronary circulation, nine had normal immediate post-laser coronary angiograms and unchanged electrocardiograms. Although the cardiovascular state of the first and third of these nine was satisfactory and stable for several hours after the procedure, their ventilation was not (it took over an hour to wean both of them off the ventilator), and both were found dead the following morning. Post-

Table 1 Energy delivery by bare fibres

\begin{tabular}{|c|c|c|c|c|c|c|}
\hline \multirow[b]{2}{*}{$\begin{array}{l}\text { Pulse } \\
\text { energy (J) }\end{array}$} & \multicolumn{6}{|c|}{ Number of perforations/pulses delivered } \\
\hline & $\begin{array}{l}\text { Dogs } \\
(2 W)\end{array}$ & $\begin{array}{l}\text { Rabbits } \\
11 \mathrm{~W}\end{array}$ & $1.5 \mathrm{~W}$ & $2 W$ & $3 W)$ & Total \\
\hline $\begin{array}{l}0.2 \\
0.5 \\
1.0 \\
2.0 \\
3.0 \\
4.0 \\
5.0 \\
6.0 \\
7.0\end{array}$ & $\begin{array}{l}0 / 1 \\
0 / 2 \\
0 / 2 \\
0 / 1 \\
0 / 1 \\
1 / 1 \\
1 / 1 \\
. . \\
. .\end{array}$ & $\begin{array}{l}\ldots \\
0 / 2 \\
\ldots \\
\ldots \\
i / 1 \\
\ldots \\
\ldots\end{array}$ & $\begin{array}{l}. \\
\ddot{0} / 1 \\
0 / 1 \\
0 / 1 \\
0 / 1 \\
. . \\
. . \\
. .\end{array}$ & $\begin{array}{l}. \\
0 / 1 \\
0 / 1 \\
0 / 1 \\
\cdots \\
\ddot{2 / 2} \\
1 / 1\end{array}$ & $\begin{array}{l}. \\
0 / 2 \\
0 / 2 \\
0 / 2 \\
0 / 3 \\
2 / 3 \\
. \\
. \\
.\end{array}$ & $\begin{array}{l}0 / 1 \\
0 / 2 \\
0 / 8 \\
0 / 5 \\
0 / 6 \\
3 / 5 \\
2 / 2 \\
2 / 2 \\
1 / 1\end{array}$ \\
\hline
\end{tabular}


Table 2 Energy delivery by balloon angioplasty catheter

\begin{tabular}{|c|c|c|c|c|c|}
\hline \multirow[b]{2}{*}{ Dog } & \multicolumn{2}{|l|}{ Angiography } & \multirow[b]{2}{*}{ Perforation } & \multirow[b]{2}{*}{ Mode of death } & \multirow{2}{*}{$\begin{array}{l}\text { Laser } \\
\text { power } \\
(W)\end{array}$} \\
\hline & Immediate & Repeat & & & \\
\hline 3 & $\mathbf{N}$ & - & Nil & $\begin{array}{l}<12 \mathrm{~h} \\
\text { anaesthetic }\end{array}$ & 2 \\
\hline 4 & Perf $3 \mathrm{~J}$ & - & Laser & $\begin{array}{l}\text { Immediate } \\
\text { laser }\end{array}$ & 1.5 \\
\hline 5 & $\mathbf{N}(\mathbf{M P})$ & - & Mechanical & $\begin{array}{l}<12 \mathrm{~h} \\
\quad \text { anaesthetic }\end{array}$ & 1.5 \\
\hline $\begin{array}{l}6 \\
7 \\
8 \\
9\end{array}$ & $\begin{array}{l}\mathbf{N} \\
\mathbf{N}(\mathbf{M P}) \\
\mathbf{N}(\mathbf{M P}) \\
\mathbf{N}(5 \mathrm{~J})\end{array}$ & $\begin{array}{l}\mathbf{N} \\
\mathbf{N} \\
\mathbf{N} \\
-\end{array}$ & $\begin{array}{l}\text { Nil } \\
\text { Mechanical } \\
\text { Mechanical } \\
\text { Nil }\end{array}$ & $\begin{array}{l}7 \text { days, killed } \\
7 \text { days, killed } \\
7 \text { days, killed } \\
\text { Immediate, } \\
\text { killed }\end{array}$ & $\begin{array}{l}3 \\
1 \\
2 \cdot 5 \\
1.5\end{array}$ \\
\hline 10 & $\mathrm{~N}_{\text {Perf } 5+5 \mathrm{~J}}$ & $\mathrm{~N}$ & $\begin{array}{l}\text { Nil } \\
\text { Laser }\end{array}$ & 10 days, laser & $\begin{array}{l}1 \\
2 \cdot 5\end{array}$ \\
\hline 11 & $N(5 \mathrm{~J})$ & 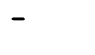 & $\mathrm{Nil}$ & $\begin{array}{l}\text { Immediate, } \\
\text { killed }\end{array}$ & 1.5 \\
\hline $\begin{array}{l}12 \\
13 \\
14\end{array}$ & $\begin{array}{l}\mathbf{N}(\mathbf{M P}) \\
\mathbf{N} \\
\mathbf{N}\end{array}$ & $\begin{array}{l}\mathbf{N} \\
\mathbf{N} \\
\mathbf{N}\end{array}$ & $\begin{array}{l}\text { Mechanical } \\
\text { Nil } \\
\text { Nil }\end{array}$ & $\begin{array}{l}10 \text { days, killed } \\
7 \text { days, killed } \\
9 \text { days, killed }\end{array}$ & $\begin{array}{l}2 \\
2 \\
2\end{array}$ \\
\hline
\end{tabular}

MP, angiographic evidence of mechanical perforation; Perf perforated; $\mathrm{N}$, normal; $(5 \mathrm{~J})$, single $5 \mathrm{~J}$ pulse delivered at initial angiography.

mortem examination did not find any blood in the pericardial space or any other evidence of laser perforation or myocardial damage. Postmortem angiograms of the lasered vessel were normal.

Thereafter the anaesthetic technique was altered. The other seven dogs recovered and survived without any complications. Repeat angiography at 7-10 days of the previously lasered vessels were all normal, and there was no change in the dogs' electrocardiograms. Postmortem examination of these seven dogs did not show any macroscopic evidence of laser perforation.

In the second of the ten dogs that received the sequential laser pulses $(1 \mathrm{~J}, 2 \mathrm{~J}$, then $3 \mathrm{~J}$ ) to the same intracoronary site, laser perforation occurred after the $3 \mathrm{~J}$ pulse. During the post-laser angiogram the dog went into ventricular fibrillation and died. Postmortem macroscopic inspection of the laser perforation site (fig 2) showed a discrete hole with little surrounding damage. After withdrawal of the fibre/ catheter device it was apparent that the tip of the optical fibre had been pushed back (by about $1.5 \mathrm{~mm}$ ) relative to the catheter tip, and that the balloon had become deformed into a banana shape such that the fibre tip was protruding obliquely from the catheter tip. In this balloon angioplasty catheter the through and balloon inflation lumens lay side by side. Such balloon deformation with oblique displacement of the fibre tip did not occur with balloon angioplasty catheters with a central through lumen that ran coaxially within the balloon inflation lumen.

Short term effects of $5 J$ pulses

In two dogs (9 and 11), because of radiographic
Bowker, Fox, Cross, Poole-Wilson, Bown, Rickards $\frac{\text { 眾 }}{\frac{D}{T}}$ contrast induced electrocardiographic instability, a市 single $5 \mathrm{~J}$ pulse was delivered at the initial general ${ }_{c}^{7}$ anaesthetic, and the dogs were killed immediately. In $\stackrel{.}{\Rightarrow}$ a third $\operatorname{dog}(10)$ it was possible to intubate the otherof main left coronary artery branch at repeat angiogra- 0 phy ten days later. In this third dog two separate $5 \mathrm{~J} \frac{\overline{0}}{\overline{0}}$ laser pulses were delivered to the same site.

In all three, there was no difference between the $\stackrel{\mathbb{D}}{\Omega}$ pre- and post-laser angiograms or electrocar-i diograms after the single $5 \mathrm{~J}$ pulse. In dog 10, however, perforation occurred after delivery of the second $5 \mathrm{~J}$ laser pulse to the same site (cumulative $\vec{\omega}$ energy dose of $10 \mathrm{~J}$ ) (fig 3). A haemopericardium? formed, but the heart continued to beat. After about? 30 minutes (during which there were no arrhyth-i mias), the animal was killed by infusion of $\triangle$ intracoronary potassium chloride. Postmortem macroscopic inspection of the laser perforation site (fig 4) showed a larger hole with more widespread?

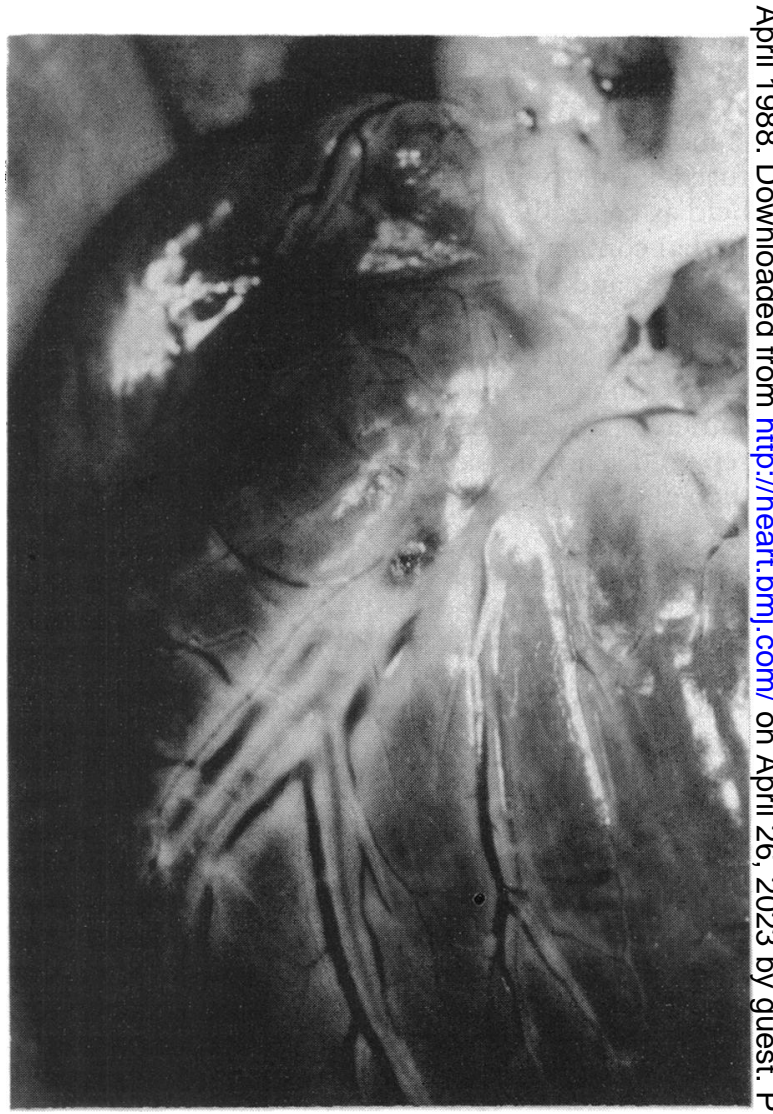

Fig 2 Pathological specimen from dog 4 showing left anterior descending coronary artery after a $3 \mathrm{~J}$ laser pulse (cumulative dose of $6 \mathrm{~J}$ ) delivered when the laser fibre had been inadvertently positioned obliquely within the vessel lumen. Compare with fig 4. 


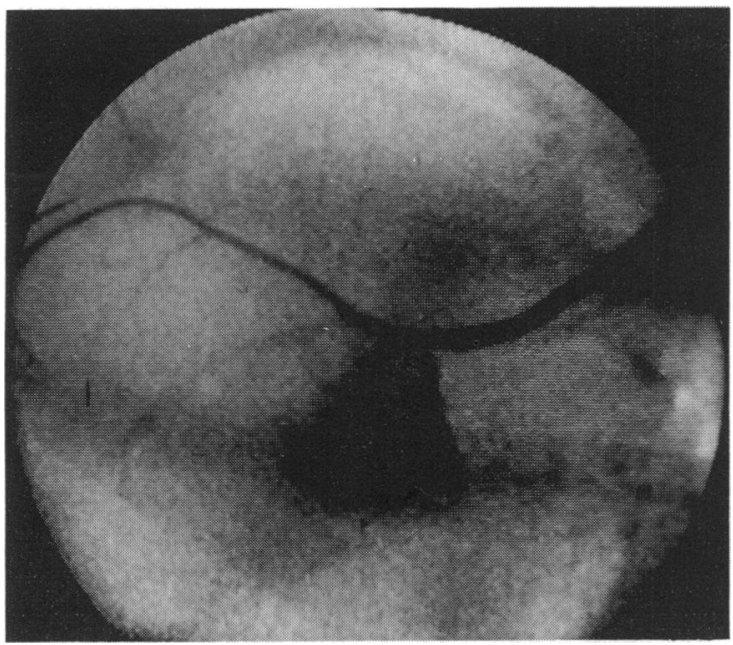

Fig 3 Post-laser left anterior descending coronary angiogram in dog 10 after delivery via an angioplasty catheter of two $5 \mathrm{~J}$ pulses to the same site. Contrast medium can be seen spurting from underside of artery, and beginning to collect in the pericardial space.

surrounding damage than was seen after the laser perforation with the inadvertently obliquely positioned fibre tip. Postmortem examination of the other two vessels (which had each received only one 5 J pulse) did not show macroscopic evidence of laser perforation.

\section{PERFORATIONS}

Throughout the delivery of the 34 different laser pulses, laser perforation only occurred on two occasions (both described above). On four other occasions there was radiographic evidence of mechanical perforation of the vessel wall by the protruding optical fibre tip during manipulation of the fibre/catheter device within the coronary circulation before any laser energy was delivered. This was shown by the appearance of a small blush of extravasated contrast medium to one side of the vessel when contrast was injected immediately before delivery of the first laser pulse (figs 5a-d).

On all four occasions there were no haemodynamic consequences, the fibre/catheter device was manipulated a centimetre or so past the point of mechanical perforation, and the sequence of laser pulses was delivered to this more distal site as described above. In all four cases the immediate post-laser angiograms were normal. Three of the four animals survived to 7-10 days, and at this time repeat angiograms of the previously lasered vessels were normal, with no evidence of the previous mechanical perforation. In one of these three dogs, postmortem examination showed a small subepicardial haematoma (fig 6). In the other two there was no postmortem evidence of vessel perforation.

One of the four instances of mechanical perforation occurred in a dog in which death was attributed to anaesthesia. Postmortem examination showed a small subepicardial haematoma at the site of mechanical perforation, but no macroscopic evidence of laser damage, nor any blood, clot or adhesions within the pericardium. A postmortem angiogram of this lasered vessel was normal.

\section{CATHETER DAMAGE}

On three occasions the fibre/catheter device was damaged during the procedure. The first occasion (already described) was when the optical fibre tip became pushed back relative to the catheter tip, such that the fibre protruded obliquely causing laser perforation.

On the other two occasions, during delivery of the first laser pulse the balloon suddenly deflated and could not be reinflated. An internal perforation between the balloon and the through lumen had occurred and contrast medium had passed via the balloon into the through lumen and out into the lumen of the coronary artery. There were no haemodynamic or electrocardiographic consequences. On one occasion the fibre had retracted relative to the catheter (while it was being manipulated to the coronary circulation) such that its tip was entirely within the tip of the catheter and on the other occasion the fibre fractured within that part of the through lumen that traverses the balloon.

All three cases of catheter/fibre damage occurred with balloon angioplasty catheters in which the through and balloon inflation lumens ran side by side. Thereafter we used only balloon angioplasty

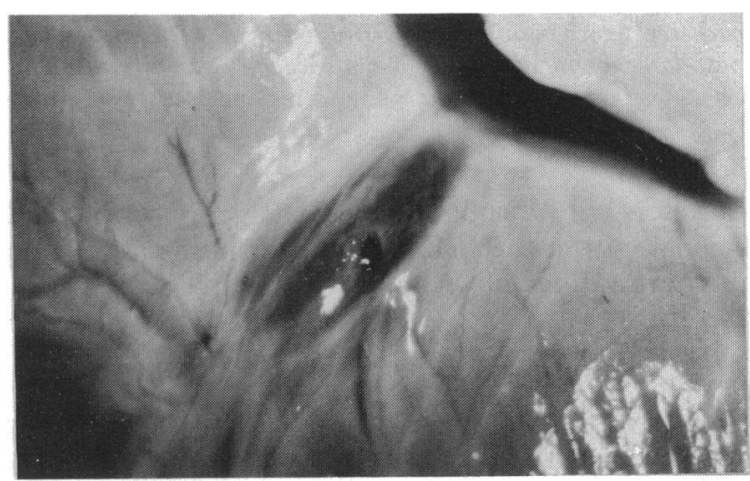

Fig 4 Pathological specimen of the perforated left anterior descending coronary artery in dog 10. Perforation occurred after delivery, via an angioplasty catheter of two $5 \mathrm{~J}$ laser pulses. Compare with fig 2. 

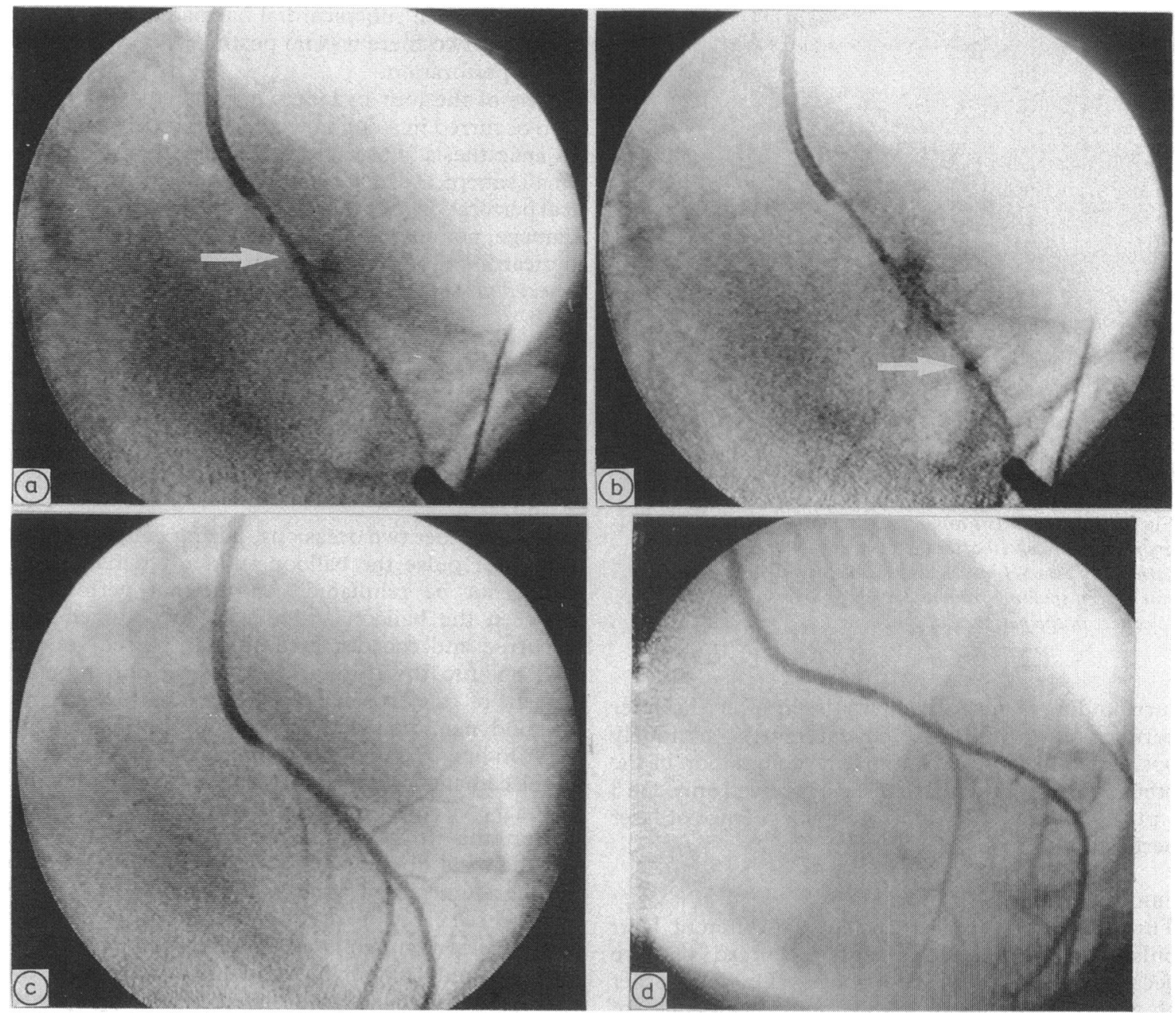

Fig 5 Mechanical perforation in dog 12. (a) Showing blush of extravascular contrast medium to right of left anterior descending artery, just downstream from distal radiographic marker (arrowed) of balloon angioplasty catheter. (b) Fibre/ catheter device manipulated distal to site of mechanical perforation (distal radiographic marker arrowed). (c) Immediate post-laser angiogram with no evidence of laser perforation or further extravasation from the mechanical perforation site.

(d) Angiogram obtained 10 days after angioplasty showing no evidence of mechanical or laser damage.

catheters with through lumens that were central and coaxial within the balloon inflation lumens, and no further catheter/fibre damage occurred.

\section{Discussion}

From a superficial examination of these data it might appear that the laser perforation threshold was higher when laser delivery was via an angioplasty catheter than when it was not. No definite conclusions can be drawn about this, however, as the presence or absence of a balloon angioplasty catheter was not the only factor that varied between delivery of energy by bare fibres and by balloon angioplasty catheters.

We used bare fibres to deliver 32 laser pulses to 32 separate sites on the luminal surface of 12 arteries during blood perfusion in open chest dogs or exposed $\stackrel{\oplus}{?}$ rabbit iliac vessels. The acute in vivo argon laser 0 perforation threshold lay between 3 and $4 \mathrm{~J}$; energy density with this fibre is about $50 \mathrm{~kJ} / \mathrm{cm}^{2}$.

We used a balloon angioplasty catheter to deliver 34 laser pulses to 13 separate sites in 13 different coronary arteries: at two sites a single $(5 \mathrm{~J})$ pulse was 


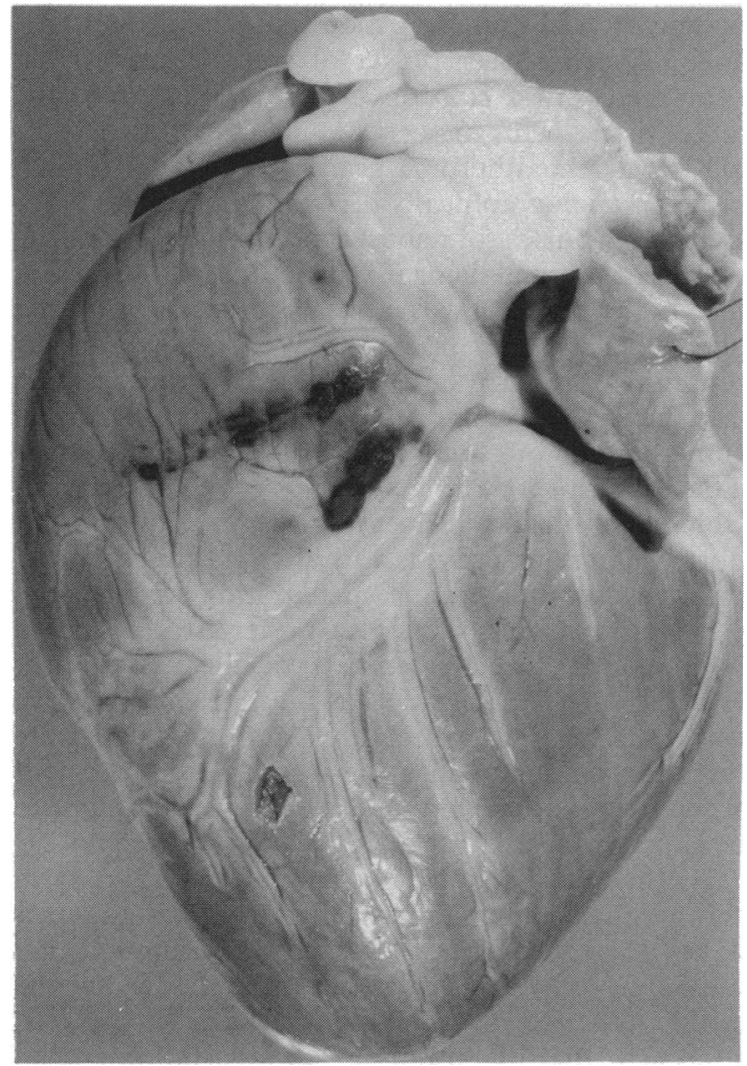

Fig 6 Pathological specimen showing subepicardial haemotoma in dog 7. This was an incidental finding when the dog was killed one week after mechanical perforation that had no sequelae. (A myocardial block was excised from the apical region post mortem.)

given, at one site two sequential pulses $(2 \times 5 \mathrm{~J})$ were given, and at ten sites three sequential pulses ( 1 $\mathrm{J}, 2 \mathrm{~J}$, and $3 \mathrm{~J}$ ) were given. The laser pulses were given during Hartmann's perfusion in closed chest dogs. With one exception, laser energy of up to $5 \mathrm{~J}$ (single pulse) or $6 \mathrm{~J}$ (cumulative dose) at one site produced no immediate angiographic or electrocardiographic abnormalities; however, a cumulative dose of $10 \mathrm{~J}$ at one site produced immediate vessel perforation.

The exception was dog 4 , in which laser perforation occurred after a $3 \mathrm{~J}$ pulse ( $6 \mathrm{~J}$ cumulative dose), and this was the only case in which deformation of the balloon had caused the fibre tip to protrude obliquely from the catheter tip. In all subsequent cases we used angioplasty catheters with a through lumen that was central and coaxial within the balloon inflation lumen, and inspection of the fibre/catheter system after laser delivery did not show any deformity or oblique protrusion of the fibre tip. In all we found a straight balloon with the fibre tip positioned centrally as it emerged from the catheter tip. Macroscopically, the perforation site in $\operatorname{dog} 4$ (fig 2) was smaller and with less surrounding damage than that produced by $10 \mathrm{~J}$ in $\operatorname{dog} 10$ (fig 4) when the fibre had remained central within the catheter tip.

Non-perforating laser pulses (of up to $3 \mathrm{~J}$ (single pulse) or $6 \mathrm{~J}$ (cumulative dose)), delivered via balloon angioplasty catheter resulted in no angiographic or electrocardiographic abnormalities at 7-10 days. The higher perforation threshold with the balloon angioplasty catheter must be the result of several factors, only one of which is the positioning of the fibre tip within the vessel lumen to reduce direct contact with the arterial wall during the cardiac cycle. Other factors are the use of closed chest dogs, sequential laser pulses, and Hartmann's perfusion with the balloon angioplasty catheter, as opposed to the use of open chest dogs, rabbit iliac vessels, single laser pulses, and blood perfusion with the bare fibre.

Initially open chest dogs were chosen so that direct intraluminal contact could be ensured and immediate vessel perforation recognised by direct visual examination. A range of pulse energies was used to find an approximate perforation threshold. Thereafter, for the sake of economy we used rabbit iliac arteries of similar size. Results were similar in both rabbits and dogs. Differences between the thermal damping of the open preparations (used with bare fibres) and that of the closed preparations (used with balloon angioplasty catheters) will influence the perforation threshold. The laser perforation in $\operatorname{dog} 4$ at an energy level equivalent to the bare fibre perforation threshold, however, suggests that the thermal damping effect is not large.

To imitate clinical practice, we used closed chest dogs with balloon angioplasty catheters, and in all but two, sequential pulses were delivered to one site. In the two in which a single $5 \mathrm{~J}$ pulse (which exceeds the bare fibre perforation threshold) was delivered to a single site, perforation did not occur. This suggests that the higher perforation threshold with an angioplasty catheter may not wholly be the result of sequential pulses.

The presence of blood enhances argon laser vaporisation, including that caused radially from the central axis of the fibre tip. ${ }^{8}$ This will have been a (perhaps major) contributory factor in the lower perforation threshold with the bare fibre. Because in clinical practice we would aim to minimise the lateral spread of thermal effect by delivering the laser energy in clear fluid we used perfusion with Hartmann's (to maintain intracoronary normokalaemia in the closed chest dogs). Dangerous localised intracoronary hyperkalaemia caused by argon laser induced haemolysis is unlikely. ${ }^{9}$

Although with our fibre/catheter device, mechan- 
ical perforation did not cause haemodynamic sequelae, it is none the less undesirable. This risk could be minimised by modifying our delivery system such that the fibre/catheter device is advanced into the coronary circulation without the fibre protruding from the catheter tip. The fibre tip could then be pushed out of the catheter tip once the catheter has been manipulated to the target lesion.

Fibre fracture and catheter damage occurred only in the region of the balloon, and only in those catheters in which the "through" and inflation lumens lay side by side, and were immediately recognisable by the failure of the balloon to inflate. But under these circumstances the catheter could be withdrawn without complication.

Percutaneous transluminal delivery of argon laser energy to the canine coronary circulation has been studied by others when a bare $200 \mu$ m core diameter fibre was used to deliver single $1 \mathrm{~J}$ or $2 \mathrm{~J}$ laser pulses to different coronary arterial sites; in nine arteries in five dogs laser perforation occurred in five and mechanical perforation in one. ${ }^{10}$ In a similar study with a bare $400 \mu \mathrm{m}$ core fibre and single laser pulses of 28 to $80 \mathrm{~J}$ at coronary sites in four dogs, immediate laser perforation occurred in all four. ${ }^{11}$ In similar work on canine intracoronary thrombus, single pulses of 3 to $30 \mathrm{~J}$ caused laser perforation in seven out of nine dogs and recanalisation in one. ${ }^{12}$ In these studies not only were the fibres of larger diameter than those used in our study (making them less flexible), but the fibres were not within a balloon angioplasty catheter. These factors, together with the higher delivered energies, would explain the high perforation rates at energies that were consistent with the perforation thresholds that we found. Also in the previous studies none of the dogs were recovered, so late follow up repeat angiography of previously lasered canine coronary arteries was impossible.

The delivery of laser energy has been studied in human peripheral ${ }^{13-15}$ and coronary ${ }^{1617}$ circulations. A bare fibre with an olive-shaped metal tip was used for percutaneous intracoronary delivery ${ }^{18-20}$ and in 14 cases there was one laser perforation and three myocardial infarctions. There are several potential dangers of laser angioplasty-acute vessel perforation, toxic byproducts of photovaporisation, ${ }^{21}$ distal embolisation, ${ }^{22}$ and delayed effects such as subsequent stenosis or aneurysm formation ${ }^{24}$ but acute vessel perforation is the most important.

The risk of vessel perforation can be reduced by (a) selective enhancement of laser light absorption by atheroma (as opposed to that of the normal arterial wall) by using differential optical absorption peaks that are either naturally ${ }^{25}$ or induced by photosensitisers, ${ }^{26}{ }^{27}(b)$ keeping the fibre central within the vessel lumen in order to reduce contact between fibre tip and arterial wall, ${ }^{23}(c)$ modifying the fibre tip, ${ }^{2829} \stackrel{{ }^{2}}{7}$ and delivering laser pulses of short duration that $c$ penetrate only a fraction of a millimetre into the $\Rightarrow$ target tissue. This may enable the operator to "nibble" away the atheroma gradually, while checking? progress angiographically between laser pulses. Very $\frac{\overline{\bar{c}}}{\mathrm{~s}}$ short laser pulses (of nanosecond duration) limit the $\frac{\text { }}{\bar{\phi}}$ subjacent thermal damage, particularly if they are at $\varrho$ the high peak powers obtainable from pulsed ultraviolet excimer lasers. ${ }^{30}{ }^{31}$ We have previously reported an in vitro dose-response relation between laser energy input and tissue penetration in normale and atheromatous human postmortem arterial wall. ${ }^{7} \mathrm{~S}$ This described a range of energy characteristics? which, if applied to delivery of laser energy from the fibre tip in contact with and at right angles to the tissue, would not produce penetration further than $0.2-1.0 \mathrm{~mm}$. The design of the present study is based on the energy characteristics of the argon laser ${ }_{-}$ established by that study. In the present study we used pulse energies which in vitro did not penetrate further than $1 \mathrm{~mm}$ into the target tissue, per $\mathrm{J}$ of argon energy delivered, and which were thought to $0_{\infty}^{\circ}$ be appropriate for "nibbling" away of atheroma.

We have now established in vivo the short termo and long term angiographic effects of such amounts of argon laser energy and we know the amount thato can safely be delivered to one site in the normalo canine coronary circulation. If this cautious $\mathbb{D}$ approach (that of "nibbling" away a millimetre of atheroma at a time without exceeding the maximum 3 safe dose for normal arterial wall) is used clinically it may reduce the risk of acute laser perforation. The? limitation of the system we have described is that the recanalised lumen that it creates is liable to be toom small for physiological blood flow. But creation of even a tiny lumen may enable operators subsequentlye. to cross those lesions which hitherto they had been unable to cross with the guide wire and balloon alone. Modified fibre tips make this appear feasible in theo peripheral circulation ${ }^{1532}$; however, further develop $\rightarrow$ ment is necessary before it can safely be applied to the coronary circulation.

This work was supported by the British Heari Foundation, and the Stanley Thomas Johnson Foun $\frac{N}{\omega}$ dation.

\section{References}

1 Gruntzig AR, Senning A, Siegenthaler WE. Non-0 operative dilatation of coronary artery stenosis, per $\frac{\mathbb{D}^{+}}{\mathrm{D}}$ cutaneous transluminal coronary angioplasty. $N$ Eng $\frac{P}{\mathbb{D}}$ J Med 1979;301:61-7.

2 Dorros G, Stertzer SH, Cowley MJ, Myler RK. Complex coronary angioplasty: multiple coronary dilata 
tions. Am J Cardiol 1984;53:126C-30C.

3 Holmes DR, Vlietstra RE, Smith HC, et al. Restenosis after percutaneous transluminal coronary angioplasty (PTCA): a report from the PTCA registry of the National Heart, Lung and Blood Institute. Am J Cardiol 1984;53:77C-81C.

4 Isner JM, Donaldson RF, Funai JT, et al. Factors contributing to perforation resulting from laser coronary angioplasty: observations in an intact human post-mortem preparation of intra-operative laser coronary angioplasty. Circulation 1985;72(suppl II):II-191-9.

5 Abela GS, Normann SJ, Cohen DM, et al. Laser recanalisation of occluded atherosclerotic arteries in vivo and in vitro. Circulation 1985;71:403-11.

6 Lee G, Ikeda RM, Theis JH, et al. Acute and chronic complications of laser angioplasty: vascular wall damage and formation of aneurysms in the atherosclerotic rabbit. Am J Cardiol 1984;53:290-3.

7 Bowker TJ, Bown SG, Poole-Wilson PA, Fox KM, Salmon PR, Rickards AF. Quantitative comparative analysis of argon and Nd-YAG laser radiation of normal and atheromatous arterial walls [Abstract]. $\mathrm{Br}$ Heart J 1985;53:101.

8 Fenech A, Abela GS, Crea F, Smith W, Feldman R, Conti CR. A comparative study of laser beam characteristics in blood and saline media. Am J Cardiol 1985;55:1389-92.

9 Bowker TJ, Cross FW, Rumsby PT, et al. Is localised intracoronary hyperkalaemia a risk of laser angioplasty? [Abstract]. Br Heart J 1985;54:637.

10 Crea F, Abela GS, Fenech A, Smith W, Pepine CJ, Conti CR. Transluminal laser irradiation of coronary arteries in live dogs: an angiographic and morphologic study of acute effects. Am J Cardiol 1986;57:171-4.

11 Lee G, Seckinger D, Chan MC, et al. Potential complications of coronary laser angioplasty. Am Heart J 1984;108:1577-9.

12 Crea F, Fenech A, Smith W, Conti CR, Abela GS. Laser recanalisation of acutely thrombosed coronary arteries in live dogs: early results. J Am Coll Cardiol 1985;6:1052-6.

13 Ginsberg R, Wexler L, Mitchell RS, Profitt D. Percutaneous transluminal laser angioplasty for treatment of peripheral vascular disease. Radiology 1985;156:619-24.

14 Geschwind HJ, Boussignac G, Teisseire B, Benhaiem N, Bittoun R, Laurent D. Conditions for effective Nd-YAG laser angioplasty. $B r$ Heart $J$ 1984;52: 484-9.

15 Cumberland DC, Sanborn TA, Tayler DI, et al. Percutaneous laser thermal angioplasty: initial clinical results with a laser probe in total peripheral artery occlusions. Lancet 1986;i:1457-9.

16 Fournial G, Choy D, Marco J, et al. Coronary artery disobliteration by laser: a peroperative study. Arch
Mal Coeur 1985;78:1061-5.

17 Livesay JJ, Leachman DR, Hogan PJ, et al. Preliminary report on laser coronary endarterectomy in patients [Abstract]. Circulation 1985;72:III-302.

18 Cumberland DC, Starkey IR, Oakley GDG, et al. Percutaneous laser-assisted coronary angioplasty [Letter]. Lancet 1986;ii:214.

19 Crea F, Davies G, McKenna W, Pashazade M, Taylor $\mathrm{K}$, Maseri A. Percutaneous laser recanalisation of coronary arteries [Letter]. Lancet 1986;ii:214-5.

20 Sanborn TA, Faxon DP, Kellett MA, Ryan TJ. Percutaneous coronary laser thermal angioplasty. $\mathrm{J} \mathrm{Am}$ Coll Cardiol 1986;8:1437-40.

21 Isner JM; Clarke RH, Donaldson RF, Aharon A. Identification of photoproducts liberated by in vitro argon laser irradiation of atherosclerotic plaque, calcified cardiac valves and myocardium. Am J Cardiol 1985;55:1192-6.

22 Case RB, Choy DSJ, Dwyer EM, Silvernail PJ. Absence of distal emboli during in vivo laser recanalisation. Lasers Surg Med 1985;5:281-9.

23 Vieilledent C, Geschwind H, Teisseire B, Boussignac G. Is laser angioplasty a safe technique? [Abstract]. Circulation 1984;70:II-266.

24 Cross FW, Bowker TJ, Bown SG. The healing process in the dog following intraluminal delivery of pulsed Nd-YAG laser energy. Br J Surg 1987;74:430-5.

25 Bowker TJ, Edwards P, Hall TA, et al. Optical transmission of normal and atheromatous arterial wall: a spectral analysis. Cardiovasc Res 1986;30:393-7.

26 Litvack F, Grundfest WS, Forrester JS, et al. Effects of haematoporphyrin derivative and photodynamic therapy on atherosclerosis. Am J Cardiol 1985; 56:667-71.

27 Murphy-Chutorian D, Kosek J, Mok W, et al. Selective absorption of ultraviolet laser energy by human atherosclerotic plaque treated with tetracycline. $\mathrm{Am} \mathrm{J}$ Cardiol 1985;55:1293-7.

28 Sanborn TA, Faxon DP, Haudenschild CC, Ryan TJ. Experimental angioplasty: circumferential distribution of laser thermal energy with a laser probe. $J \mathrm{Am}$ Coll Cardiol 1985;5:934-8.

29 Bowker .TJ, Cross FW, Bown SG, Rickards AF. Reduction of vessel wall perforation by the use of sapphire tipped optical fibres in laser angioplasty [Abstract]. Br Heart J 1987;57:88.

30 Dekelbaum LI, Isner JM, Donaldson RF, et al. Reduction of laser induced pathologic tissue injury using pulsed energy delivery. Am J Cardiol 1985;56:662-7.

31 Bowker TJ, Cross FW, Rumsby PT, Gower MC, Rickards AF, Bown SG. Excimer laser angioplasty: quantitative comparison in vitro of three ultraviolet wavelengths on tissue ablation and haemolysis. Lasers Med Sci 1986;1:91-9.

32 Cross FW, Bowker TJ. Percutaneous laser angioplasty with sapphire fibretips [Letter]. Lancet 1987;i:330. 